\title{
Ensino ou aprendizagem a distância
}

\section{Distantly teaching or apprenticeship}

\author{
Fernando Becker* \\ Tania B. Iwaszko Marques**
}

\begin{abstract}
RESUMO
O ensino a distância tem sido apontado como uma alternativa à formação de professores. Alguns cuidados, porém, devem ser tomados. As novas tecnologias possibilitam, entre outras coisas, rapidez e agilidade na troca de informações, no acesso a novidades, no contato com realidades de outra forma inatingíveis, mas não basta a "magia" tecnológica para democratizar a informação; e sobretudo, educação não se faz apenas com trânsito eficiente de informação. No que concerne ao ensino a distância, devese pensar, tal como acontece no ensino presencial, na epistemologia que fundamenta o trabalho pedagógico. Mesmo à distância, continua valendo a idéia de que o ensino será exercido nos limites da compreensão de como se dá o conhecimento. A grande ilusão do ensino convencional reside na crença de que se aprende porque se interiorizam imagens. Na visão que propomos, é a ação que dá significado às coisas. Dessa forma, o ensino só terá sentido quando for centrado na aprendizagem. Portanto, não se deve substituir a reflexão pedagógica pelo encantamento com a tecnologia. Com os avanços que o século XX nos legou, deveríamos estar pensando e tirando vantagem das ilimitadas possibilidades das concepções mais avançadas de aprendizagem. Em vez de ensino a distância deveríamos pensar em aprendizagem à distância.

Palavras-chave: Aprendizagem, ensino a distância, epistemologia genética.
\end{abstract}

* Professor titular de Psicologia da Educação na Faculdade de Educação e no PPGEdu da UFRGS. Doutor em Psicologia Escolar pela USP. fbecker@edu.ufrgs.br

** Psicóloga, professora na Faculdade de Educação da UFRGS. Doutoranda em Educaçãona UFRGS. f.becker@terra.com.br 


\begin{abstract}
Remote teaching has been pointed out as an alternative to teachers education. However, we should be careful about it. New technologies provide, among other things, speed and agility in the exchange of information; in the access to novelties; in the contact with realities which otherwise would be unattainable. But the technology "magic" itself is not enough to democratize information, and education is not achieved through the efficient traffic of information. Regarding to remote teaching one should think, as it happens in the attendance teaching, about the epistemology that gives foundation to the pedagogical work. Even at distance, it still prevails the idea that the teaching will be accomplished within the comprehension limits of how knowledge takes place. The great illusion of conventional teaching lies in the belief that learning is achieved through the internalization of images. We propose a view where action gives significance to things. This way, teaching will make sense only when it is centered in learning. Therefore, one should not replace the pedagogical reflection by the technology enchantment. With the advances that the $20^{\text {th }}$ Century has bequeathed us we one should think about taking advantage of the unlimited possibilities of the most advanced learning conceptions. Instead of remote teaching one should think about remote learning.

Key-words: Learning, remote teaching, genetic epistemology.
\end{abstract}

\title{
Introdução
}

O ensino a distância tem sido apontado como uma alternativa à formação de professores em um país de proporções continentais como o Brasil. Nosso país apresenta uma distribuição desigual de acesso ao ensino, com contrastes muito marcantes entre regiões com crescimento industrial e nível de vida equivalentes ao primeiro mundo e outras regiões de extremo atraso e miséria. A educação a distância apresenta-se como uma tentativa de eliminar, do ponto de vista educacional, essas diferenças abissais. Para não citar aqueles que pretendem, com ela, apenas, diminuir os custos com a educação. São numerosos os defensores dessa modalidade que, segundo alguns, democratizaria enormemente o acesso ao ensino. 
É preciso que, sem abandonar o necessário relacionamento direto da comunidade com a população, sem cair na folia do tecnicismo, a universidade ponha os novos instrumentos a serviço da educação de cada aluno e leve estes ensinamentos a uma educação global como em nenhum outro momento foi possível (BUARQUE, 2000, p. 49).

Apesar de todas as vantagens que o ensino a distância possa oferecer, alguns cuidados devem ser tomados. Qualquer novidade tende a provocar euforias e medos. É preciso conhecer e analisar esses sentimentos para que não assumam um caráter de problema resolvido, por um lado e por outro de reação paralisante. Aqueles que trabalham com esse tipo de ensino devem estar atentos, portanto, a alguns problemas.

\section{$O$ canto da sereia}

Qualquer nova tecnologia tende a causar euforia; uma sensação de que a tecnologia por si só irá resolver nossas dificuldades. Responde-se a isso, colocando a tecnologia no seu devido lugar. Primeiramente, a sua importância deve ser relativizada, ou seja, devemos construir a consciência de que, sozinha, ela nada irá produzir; dependerá sempre da forma como será utilizada. Segundo, não podemos confundir ensino com troca de informações. Constatamos uma grande euforia em torno das novas tecnologias que possibilitam as relações, em tempo real, entre pessoas de regiões distantes. É claro que ficamos fascinados, por exemplo, ao ver Bob Dylan (que se encontrava em turnê pela Austrália) receber, em tempo real, o seu Oscar de melhor música, em cerimônia realizada em Los Angeles. Ele fez-se presente, não só na cerimônia de Los Angeles (via telão), mas em milhões de televisores do mundo inteiro.

As novas tecnologias possibilitam, entre outras coisas, rapidez e agilidade na troca de informações, no acesso a novidades, no contato com realidades de outra forma inatingíveis. $\mathrm{O}$ acesso à informação é condição fundamental para a democratização. Uma das primeiras providências de um governo ditatorial é controlá-la. Há poucos anos, grandes investimentos foram destinados para alocar grande número de televisores e antenas parabólicas em es- 
colas públicas do país. Empreendimento louvável. O não louvável está em acreditar que a presença dessa tecnologia resolverá, por si mesma, os problemas da educação dispensando-se, em nome dela, a formação continuada dos professores. Numa palavra, não basta a "magia" tecnológica para democratizar a informação; e educação não se faz apenas com trânsito eficiente de informação.

No que concerne ao ensino a distância, devemos pensar, tal como acontece no ensino presencial, na epistemologia que fundamenta o trabalho pedagógico (BECKER, 2001), pois, para aquele continua valendo o que vale para este. Mesmo a distância, continua valendo a idéia de que o ensino será exercido nos limites da compreensão de como se dá o conhecimento: será que o aluno é compreendido como um ser passivo que apenas incorpora informações vindas de fora; ou, sua atividade é compreendida como restrita apenas a interiorizar estímulos; ou será, ao contrário, um sujeito que constrói por que age, por que transforma e ao transformar se transforma por que cria e recria e inventa? O aluno é concebido como alguém que, perante um programa de ensino, elabora perguntas, critica conteúdos, questiona formas de abordagem, relaciona o conteúdo proposto com outros conteúdos, relaciona os conteúdos com os fenômenos observados no cotidiano, constrói formas inéditas sintetizando sua experiência e sua história individual?

\section{Ação, operação e imagem}

No texto “A evolução dos métodos de ensino", no seu livro Psicologia e pedagogia, PIAGET (1969) chama a atenção, sem conhecer a Internet ou a rede mundial de computadores, para o fascínio que o ensino tecnicista desperta. Afirma que "Tais métodos [...] constituem, na verdade, um progresso em relação aos processos puramente verbais ou formais do ensino. Mas, de modo algum são suficientes para desenvolver a atividade operatória" (p. 78). $\mathrm{Na}$ verdade, esses métodos valorizam os aspectos figurativos do pensamento em detrimento dos aspectos operativos. $\mathrm{O}$ autor ainda traça uma crítica ao uso de recursos audiovisuais: 
[...] uma pedagogia fundada na imagem, ainda quando enriquecida pelo dinamismo aparente do filme, aparece inadequada para a formação do construtivismo operatório, porque a inteligência não se reduz às imagens de um filme [...] existe um verbalismo da imagem, assim como existe um verbalismo da palavra e, confrontados com os métodos ativos, (eles) apenas substituem [...] o verbalismo tradicional pelo verbalismo mais elegante e mais refinado (p. 80) [da imagem].

Sabemos o quanto a imagem mental, com a colaboração específica da percepção, subsidia a capacidade operatória do ser humano. Sabemos, também, o quanto a imagem, não originada da percepção, mas criada pelas estruturas operatórias, originada, pois, da atividade conceitual do sujeito, viabiliza o trabalho da razão. Para compreender melhor essa relação podemos dizer que assim como a razão tende a esvaziar-se sem a percepção, a percepção é caótica sem a razão. O neurologista SACKS (1997) narra o caso de Virgil que ilustra muito bem essas relações. Trata-se de um rapaz cego praticamente desde o nascimento que foi submetido a uma cirurgia em que recupera a visão.

Ele construíra seu mundo inteiramente a partir de informações não visuais, e a súbita introdução de estímulos visuais o lançou em um estado de choque e confusão. Virgil foi esmagado pelas novas sensações sensações visuais -, não conseguindo compreendê-las, dar a elas alguma ordem ou significado (p. 210).

Tal experiência é exemplarmente dramatizada no filme À primeira vista, onde percebemos como o excesso de estímulos, para o qual o sujeito não possuía estruturas de assimilação poderia ser enlouquecedor.

Retomando a questão dos aspectos figurativo e operativo do pensamento, podemos dizer que os termos figurativo e operativo opõem-se ao mesmo tempo em que se complementam. "Guiado pela percepção e sustentado pela imagem, o aspecto figurativo da representação desempenha um papel preponderante [...] no pensamento 'pré-operatório' da criança de 2 a 7 anos, antes que se constituam as operações”. (Piaget, 1960, apud Montangero; Maurice-Naville, 1998, p. 209). 
A imagem mental não pode, nem na sua mais simples acepção, ser entendida como reprodução ou cópia perceptiva do objeto. Ela é, sempre, produto da atividade do sujeito. "A imagem mental é um produto da interiorização dos atos de inteligência" (PiAgEt, 1936, p. 132). Interiorização das ações, dos esquemas de ações ou das coordenações das ações e não, apenas, interiorização das percepções e muito menos interiorização exclusiva das percepções. A interiorização das ações é indefinidamente mais complexa que a interiorização de conteúdos perceptivos; além disso, esta interiorização depende daquela.

Assim, para Piaget, "a imagem [...] constitui um decalque, não do próprio objeto, mas das acomodações próprias da ação que incide sobre o objeto" (Piaget e Inhelder, 1948a, p. 348). Que não se entenda "objeto" como, apenas, coisa material, manuseável. "Objeto", na epistemologia, designa a totalidade do meio físico e social; isto é, tudo o que se opõe, como diferente, ao sujeito; ou ainda, tudo o que o sujeito representa, concebe, tematiza, conceitua. Fazem parte do mundo do objeto as coisas do mundo físico, o conjunto das relações sociais, as linguagens, o imaginário, os conceitos desde os mais precários do senso comum até os mais elaborados das ciências, da filosofia, da literatura etc.

Por mais que a imagem pareça ser uma cópia dos objetos, ela é, de fato, o produto da atividade do sujeito; especificamente, produto da acomodação. $\mathrm{E}$, nos estágios mais avançados, produto da atividade operatória, como acontece com os modelos científicos e filosóficos. É por isso que classificamos como ilusão a crença de que a transmissão de imagens produz, por si mesma, aprendizagem. Afirmamos o contrário: uma imagem só tem sentido se ela for compreendida pelo sujeito, isto é, assimilada aos seus esquemas de ação ou às suas estruturas operatórias. Funda-se aqui nossa crítica à crença na indefinida capacidade de ensino dos recursos audiovisuais - televisão, videocassete, internet.

\section{A imagem ensina?}

A grande ilusão do ensino convencional reside na crença largamente professada de que se aprende por que se interiorizam imagens, imagens-cópia de um conteúdo exposto pelo professor mediante giz e lousa, mediante um retroprojetor, um projetor de slide, um monitor ligado a um vídeocassete ou a um computador munido de um $\mathrm{CD}$, um data-show conectado a um compu- 
tador ou um computador conectado à rede de computadores. Entretanto, “[...] não é a imagem que determina as significações; é a própria ação assimiladora que constrói as relações, cuja imagem não é outra coisa que o símbolo" (PiAget; InHelder, 1948a, p. 540). É a ação que dá significado às coisas. A ação é criadora de significados. A percepção, tal como as sensações, é significada pelos esquemas de ação e não o contrário. Ações materiais e ações conceituais, ações físicas e ações mentais, ações realizadas fisicamente e ações realizadas mentalmente, ações práticas e ações teóricas, ações reais e ações simbólicas ou formais.

Alunos de licenciaturas foram solicitados, em aula de psicologia da aprendizagem, a olhar, pela janela do sexto andar do prédio da faculdade, para o parque extenso que se descortinava a pequena distância. Alguns deles viram prédios além das árvores, outros viram árvores aquém dos prédios, outros ainda viram os morros com torres de emissoras de televisão e um, nativo de Porto Alegre, disse que nunca vira as árvores e surpreendeu-se ao ouvir o professor falar em jacarandás, paineiras, eucaliptos, guapuruvus, cinamomos e até em palmeiras reais. Por outra janela, do lado oposto do mesmo prédio, os alunos viram automóveis, ônibus, transeuntes, uma praça, um colégio, um túnel, um monumento, prédios e os alunos da escola de artes viram, predominantemente, uma igreja e um hospital de estilo colonial português. Podemos dizer que o cérebro "manda" os olhos verem o que a mente deseja ver. A mente, ao mesmo tempo razão e emoção, é o produto de tudo o que o corpo está fazendo e percebendo nesse momento considerando toda a história do indivíduo. Os estímulos, por si sós, independentes dos esquemas ou das estruturas do sujeito, nada significam.

A hegemonia é, pois, exercida pela ação e não pela imagem, por mais importante que seja esta. "A imagem não é o prolongamento da percepção como tal, mas da atividade perceptiva..." (Piaget, 1945, p. 79). Isso significa que "[...] a imagem mental é apenas um símbolo e não um conhecimento em si mesma" (PiAgEt; Beth, 1961, p. 231). Reduzir o conhecimento a imagens que podem ser transmitidas, de uma pessoa a outra, é a ilusão de todo ensino centrado nele mesmo - inclusive do ensino a distância. O ensino só tem sentido quando for centrado na aprendizagem. Entre uma imagem visual e a aprendizagem do conteúdo dessa imagem, situa-se um conjunto nada desprezível de ações - aproximações/distanciamentos, perguntas/respostas, detalhamentos/ totalizações etc. Tal imagem nada transmite por si mesma. "[...] uma imagem visual constitui uma imitação interior ou interiorizada de ações que incidem sobre os objetos imaginados" (PIAGET, INHELDER; SZEMINSKA, 1948b, p. 22). Uma imagem visual produz aprendizagem na medida da ação do sujeito da 
aprendizagem sobre ela, tais como, ações de decomposição/recomposição, análise/síntese, coordenação/diferenciação etc. Na medida, pois, em que o sujeito recria para si essa imagem impondo a ela inumeráveis transformações.

Rejeitando qualquer concessão ao senso comum, Piaget (1973) supera a concepção de aprendizagem-cópia, que teima em sobreviver na escola, subestimando a capacidade operatória do sujeito da aprendizagem e manifestando-se no ensino a distância:

É necessário compreender bem [...] que uma operação não é a representação de uma transformação: ela é, em si mesma, uma transformação do objeto, mas que pode ser executada simbolicamente, o que não é, de forma alguma, a mesma coisa. Uma transformação permanece, então, uma ação e não se reduz nem a uma figura e nem a um símbolo (Piaget, 1960, apud Montangero; Maurice-Naville, 1998, p. 212).

Mas, a operação não pode ser reduzida à representação da ação pois ela é de fato uma ação interiorizada, isso é, uma ação tornada simbólica. "A operação não é uma representação de uma ação: ela é, propriamente falando, ainda uma ação, já que ela é construtora de novidades, mas é uma ação 'significante' e não mais física, pois as ligações que ela utiliza são de natureza implicativa e não mais causal” (Piaget, 1974, p. 241).

O sujeito da aprendizagem, entendido como um repositório automático de símbolos, provenientes do mundo dos estímulos, é fragmentado (MARcuse, 1987) e, como tal, incapaz de atividade autônoma. Na verdade, o sujeito da aprendizagem é ativo: perante os objetos materiais, exige manipulação; diante da fala, cobra o exercício do direito à palavra; perante o símbolo, esforçase para representar; ao vislumbrar um espaço, movimenta-se; ao descortinar o tempo, sonha... Cabe ao programador do ensino a distância o grande desafio de, para muito além da organização e seriação dos conteúdos, imaginar e sugerir, de forma interessante, ações e operações para que o sujeito da aprendizagem produza todo tipo de transformação até conseguir construir para si esses conteúdos e, inclusive, as relações pedagógicas nas quais se inserem suas ações; até assimilar os conteúdos e as relações como algo significativo.

Todas as dificuldades que tendem a ocorrer em sala de aula, com a presença física do aluno, poderão ocorrer, com mais razão, em encontros virtuais. Portanto, não podemos substituir a reflexão pedagógica pelo encantamento com a tecnologia. Continuam valendo para o ensino a distância as 
mesmas preocupações, teóricas e práticas, epistemológicas, psicológicas e pedagógicas, postas pelo ensino presencial, além das específicas daquela modalidade de ensino.

\section{A imagem copia, a ação cria}

Piaget denomina "intuitivos" os métodos que priorizam as imagens. Para a teoria da Gestalt, por exemplo, podemos justificar o elogio a esses métodos: para ela a inteligência é reduzida à percepção e tudo se resume em constituir uma "boa forma" perceptiva, uma boa imagem; desconsidera, pois, todo o processo de construção realizado pela ação do sujeito. Mesmo usando as tecnologias mais avançadas, se ficarmos apenas no terreno das formas imagéticas e não avançarmos na direção do plano das operações mentais ou das ações interiorizadas, não se verificará o tão esperado avanço no ensino - avanço que deve priorizar a construção, a operação mental, e não a mitológica transmissão; deve, portanto, centrar-se na aprendizagem e não no ensino. A educação não tem mais o direito de limitar-se à ilusória transmissão de imagens, seja por meios mais primitivos, seja por meios de alta resolução tecnológica. "[...] a operação é irredutível às 'formas' perceptivas ou imagéticas e que, por via de consequiência muito direta, os métodos pedagógicos intuitivos permanecem num plano bem inferior aos métodos operatórios ou ativos" (PIAGET, 1976, p. 81).

É importante, pois, levar em conta que no ensino a distância continuam valendo os cuidados que se tem com a aprendizagem em cursos presenciais. A possibilidade tecnológica de um curso a distância não é licença para que a aprendizagem seja entendida à maneira empirista, ou seja, como repasse de informações mediante transmissão de imagens; pior, ainda, quando essas imagens são apenas textos. O grande desafio é utilizar a tecnologia como aliada e não como substituta da riqueza do processo de construção do conhecimento que se dá na ação do sujeito, mesmo quando mediada pela máquina. Não se tem o direito de professar a ilusão de que a máquina irá efetivar a aprendizagem pelo aluno. A tecnologia da Internet, dos grupos de discussão, das reuniões a distância em tempo real não pode se resumir à transmissão de informações. Isso reduziria as possibilidades do ensino a distância à apenas uma versão pós-moderna do ensino por correspondência; o que seria, sob todas as formas, lamentável. 
Na década de 50, Skinner lança Tecnologia do ensino no qual propõe o método de Instrução programada tão conhecido entre nós. Juntamente com Holland, em A análise do comportamento, aplica ao conteúdo de sua teoria os princípios desse método. Esse método possibilitaria o trabalho individual e dispensaria a presença em sala de aula e o encontro com professores. Na verdade, propunha, através de um método cuidadosamente elaborado, um trabalho de condicionamento. Por trás de toda a sofisticação visava apenas a automatização de respostas, semelhante àquela buscada quando alguém memoriza a tabuada, sem entender o significado da soma ou da multiplicação, ou o algoritmo da raiz quadrada.

Que a educação a distância não se transforme numa versão maquiada da ultrapassada instrução programada, já criticada há tanto tempo na educação brasileira! Cabe lembrar que esta invenção de Holland e Skinner chegou ao Brasil no bojo das reformas de ensino implementadas pela ditadura militar, no fim dos anos 60 e início dos 70 .

\section{Aprendizagem lato sensu e aprendizagem stricto sensu}

Impõe-se, aqui, uma distinção que permite diferenciar formas de aprendizagem. Em Aprendizagem e conhecimento, Piaget (1959) distingue diferentes caminhos de formação dos conhecimentos, salientando a diferença entre aprendizagem lato sensu e stricto sensu. "No sentido restrito, só falaríamos de aprendizagem na medida em que um resultado (conhecimento ou atuação) é adquirido em função da experiência" (p. 52). Por outro lado, reserva a expressão "aprendizagem no sentido amplo" (p. 54) para a união das aprendizagens no sentido estrito com os processos de equilibração. Tal diferenciação pode ajudar aqueles que reduzem o ensino à cobrança de uma aprendizagem no sentido estrito (próximo do sentido do learning).

Nessa obra Piaget trata das relações entre aprendizagem e desenvolvimento pelas relações entre aprendizagem no sentido estrito e no sentido amplo. A aprendizagem no sentido estrito inclui toda aprendizagem do senso comum (aquisição de conteúdos externos ao sujeito), enquanto a aprendizagem no sentido amplo obtém-se pela síntese das aprendizagens no sentido estrito e das aprendizagens no sentido amplo; isto é, a síntese das aprendizagens no sentido estrito com o processo de equilibração ou de abstração 
reflexionante que se realiza na medida em que o sujeito apropria-se dos mecanismos íntimos das próprias ações ou das coordenações de suas ações.

Mas, devido a essas interações entre a assimilação e a acomodação, a aprendizagem s.str. (sentido estrito) e a equilibração constituem esse processo funcional de conjunto que podemos chamar a aprendizagem s.lat. (sentido amplo) e que tende a se confundir com o desenvolvimento (Piaget, 1959, p. 86).

Portanto, para Piaget, como para as pesquisadoras InHELDER, Bovet; SiNCLAIR (1974), o processo de aprendizagem deve ser radicalmente vinculado ao processo de desenvolvimento ou aprendizagem no sentido amplo. Desvinculado dele, não passará de treinamento - ou aprendizagem no sentido estrito - e este, como dizem essas autoras ("um treino verbal pode, facilmente, ser ilusório", p. 116), não passará de ilusão. Trata-se, pois, da compreensão de que há uma relação dialética entre aprendizagem e desenvolvimento; e não, apenas, a aprendizagem "puxando" o desenvolvimento, o que reforçaria o verbalismo da escola. Para Piaget, a aprendizagem desafia o desenvolvimento a reconstruir suas estruturas e o desenvolvimento desafia a aprendizagem a dirigir-se para novos conteúdos. Em outras palavras, cada um desses processos demanda o outro. A aprendizagem traz novidades para o desenvolvimento ou aprendizagem no sentido amplo (construção de estruturas), assim como o desenvolvimento abre possibilidades para novas aprendizagens no sentido estrito (assimilação de conteúdos). Dizendo de outro modo, só podemos aprender um conteúdo se tivermos construído previamente uma estrutura capaz de assimilar esse conteúdo; essa estrutura prévia foi construída, por sua vez, mediante a assimilação de outros conteúdos.

Não se trata, pois, de acabar com o conteúdo curricular fornecido pelas ciências para privilegiar conteúdos não formalizados da cultura, nem se centralizar exclusivamente no conteúdo, mas de escolher criteriosamente conteúdos que têm demonstrado, em experimentações psico-pedagógicas, constituir-se em melhores caminhos para a construção das estruturas cognitivas desejadas. A escola precisa aprender a trabalhar com a dialética forma/conteúdo ou estrutura/conteúdo e superar, de uma vez por todas, a tradicional centração simplista no conteúdo. Aqui, faz sentido esta afirmação de PiageT (1964, apud Montangero; Maurice-Naville, 1998): "se não existe gênese 
sem estrutura, muito menos existe estrutura sem gênese" (p. 68); ou esta outra: "toda construção é o produto de uma compensação com relação às perturbações que lhe deram origem" (Piaget, 1959, p. 20).

Isso tudo leva-nos ao questionamento das pedagogias cuja função é a transmissão de informações e, ao mesmo tempo, ao postulado de um novo ensino. Um ensino (BECKER, 2001) que tenha como compromisso fundamental:

1. Sondar a estrutura cognitiva do sujeito da aprendizagem como condição de qualquer prática docente; e sondá-la por intermédio de práticas centradas na atividade discente;

2. Instaurar a fala, no sentido das práticas de pesquisa e da pedagogia autogestionária, apoiada por PiAget $(1968,1969)$, ou do diálogo ou relação dialógica, de Freire;

3. Transformar radicalmente os meios de avaliação; esta será compreendida como correção ou controle ativos próprios da equilibração, cujo processo auto-regulado implica erro em todos os níveis.

\section{Ensino e reprodução do antigo; aprendizagem e criação do novo}

As possibilidades do ensino a distância devem ser concebidas dentro dos caminhos abertos pelas epistemologias críticas e pedagogias relacionais que apostam no desenvolvimento do sujeito pela sua própria atividade cooperativa. Elas não devem ser reduzidas aos tacanhos e melancólicos limites da concepção de conhecimento-cópia ou transmissão de informações, cuja mal disfarçada intenção é criar e estabelecer formas de controle de comportamento que costumam transformar-se, no cotidiano escolar, em formas de opressão, em cerceamento da criatividade.

Com os avanços que o século XX nos legou, deveríamos estar pensando e tirando vantagem das ilimitadas possibilidades das concepções mais avançadas de aprendizagem. Lamentavelmente estamos reeditando, com a força da tecnologia dos espaços virtuais, a retrógrada hegemonia do ensino, o que por si só denuncia a fragilidade das concepções de aprendizagem professadas nesse meio. Em vez de ensino a distância deveríamos estar pensando, decididamente, em aprendizagem a distância. 


\section{REFERÊNCIAS}

BECKER, F. A epistemologia do professor: o cotidiano da escola. 9. ed. Petrópolis: Vozes, 2001.

BUARQUE, C. A aventura da universidade. 2. ed. São Paulo: Editora da Universidade Estadual Paulista, 2000.

HOLLAND, J.; SKINNER, B. F. A análise do comportamento. São Paulo: Herder e Edusp, 1969.

INHELDER, B.; BOVET, M.; SINCLAIR, H. Aprendizagem e estruturas do conhecimento. São Paulo: Saraiva, 1977.

MARCUSE, H. El hombre unidimensional: ensayo sobre la ideologia de la sociedad industrial avanzada. 2. ed. Barcelona: Ariel, 1987.

MONTANGERO, J.; MAURICE-NAVILLE, D. Piaget ou a inteligência em evolução. Porto Alegre: Artmed, 1998.

PIAGET, J. O nascimento da inteligência na criança. Rio de Janeiro, Zahar, 1970. Originalmente publicada em 1936.

. La construction du réel chez l'enfant. Neuchâtel: Delachaux et Niestlé, 1937.

. A formação do símbolo na criança. 3. ed. Rio de Janeiro: Livros Técnicos e Científicos, 1990. Originalmente publicada em 1945.

.; INHELDER, B. La représentation de l'espace chez l'enfant. Paris: P.U.F., 1948a. (A representação do espaço na criança. Porto Alegre: Artmed).

.; INHELDER, B; SZEMINSKA, A. La géometrie spontanée chez l'enfant. Paris: P.U.F., 1948b.

. Aprendizagem e conhecimento. Rio de Janeiro: Freitas Bastos, 1974. Originalmente publicada em 1959.

.; BETH, E. W. Epistémologie mathématique et psychologie. Essai sur les relations entre la logique formelle et la pensée réelle. Paris: P.U.F., 1961 (EEG, XIV).

. Psicologia e pedagogia. 4. ed. Rio de Janeiro: Forense, 1976. Originalmente publicada em 1969.

. Problemas de psicologia genética. Rio de Janeiro: Forense, 1973. Originalmente publicada em 1972.

. A tomada de consciência. São Paulo: Edusp/Melhoramentos, 1977. Originalmente publicada em 1974. 
. Fazer e compreender. São Paulo: Edusp/Melhoramentos, 1978. Originalmente publicada em 1974.

. Abstração reflexionante; relações lógico-aritméticas e ordem das relações espaciais. Porto Alegre: Artes Médicas, 1995. Originalmente publicada em 1977.

SACKS, O. A ilha dos daltônicos. São Paulo: Companhia das Letras, 1997.

SKINNER, B. F. Tecnologia do ensino. São Paulo: E.P.U., 1975.

Texto recebido em 10 de fev. 2002 Texto aprovado em 22 de abr. 2002 